\title{
Editorial \\ Editorial Catalysts: Special Issue on Heterogeneous Catalysis for Valorization of Lignocellulosic Biomass
}

\author{
Cristina García-Sancho ${ }^{1, *(D)}$ and Rafael Luque ${ }^{2}$ (D) \\ 1 Departamento de Química Inorgánica, Cristalografía y Mineralogía (Unidad Asociada al ICP-CSIC) Facultad \\ de Ciencias, Universidad de Málaga, Campus de Teatinos, E-29071 Málaga, Spain \\ 2 Departamento de Química Orgánica, Universidad de Córdoba, Campus de Rabanales, \\ Edificio Marie Curie (C-3), Ctra Nnal IV-A, Km 396, E-14014 Córdoba, Spain; rafael.luque@uco.es \\ * Correspondence: cristinags@uma.es
}

check for updates

Citation: García-Sancho, C.; Luque, R. Editorial Catalysts: Special Issue on Heterogeneous Catalysis for Valorization of Lignocellulosic Biomass. Catalysts 2021, 11, 649 . https://doi.org/10.3390/catal11060649

Received: 27 April 2021

Accepted: 10 May 2021

Published: 21 May 2021

Publisher's Note: MDPI stays neutral with regard to jurisdictional claims in published maps and institutional affiliations.

Copyright: (c) 2021 by the authors. Licensee MDPI, Basel, Switzerland. This article is an open access article distributed under the terms and conditions of the Creative Commons Attribution (CC BY) license (https:// creativecommons.org/licenses/by/ $4.0 /)$.
Modern life is currently based on the consumption of energy and chemicals coming from fossil fuels, mainly produced by the petrochemical industry. Considering that this energy demand will be doubled in 2035, the drastic depletion of fossil resources and the environmental hazards that these resources involve, the search and development of renewable resources has attracted worldwide attention in recent years in order to avoid global warming and its consequences. In this sense, the use of biomass is a promising alternative to fossil resources since it is a unique renewable carbon source that can be employed for the production of both biofuels and valuable chemicals. However, the type of biomass must be properly selected since it could interfere with the food industry, which would lead to an increase in food cost, provoking speculation and social imbalances. Among different types of biomass, lignocellulosic biomass possesses great potential as a sustainable and renewable feedstock due to its inexpensive nature and its high availability and low impact on the food industry. Lignocellulose, mainly based on forestry and agricultural waste, is considered as a promising and environmentally friendly raw material, with an approximate production about 200 billion tons [1].

Lignocellulosic biomass is mainly composed of polysaccharides ( $30-50 \%$ cellulose, 20-35\% hemicellulose, $15-30 \%$ lignin), together with minor amounts of other materials (e.g., pectin, proteins, and inorganic salts). In recent years, significant efforts have been devoted to optimizing the integrated fractionation of lignocellulose into its main components [2]. Each component possesses specific properties, and hemicellulose and cellulose are mainly employed as sources of carbohydrates and lignin as a starting material for aromatics production. Different value-added chemicals and high-quality fuel products can be generated from lignocellulosic biomass, including organic acids (e.g., gluconic acid, formic acid, lactic acid, levulinic acid) and alcohols (sugar alcohols, ethylene glycol, and propylene glycol) from cellulose, furfural-based compounds (e.g., 5-hydroxymethylfurfural and furfural) from cellulose and hemicellulose, and various aromatic chemicals from lignin. Moreover, some of these lignocellulose-derived chemicals can be considered as platform chemicals that can be converted to other value-added compounds through various reaction routes.

In this context, the use of catalysts in order to improve catalytic performance and reaction conditions is considered of great interest. Traditionally, homogeneous catalysts are utilized in these processes, mainly in industry. However, these types of catalysts usually involve environmental and economic problems, with it also being difficult to handle and recover them. The search of greener solid acid catalysts as alternatives to homogeneous catalysis is of primary importance.

It is obvious that excellent research is being performed worldwide on the use of heterogeneous catalysts for several reactions related to the valorization of lignocellulosic biomass. This Special Issue compiles key processes in which authors employed different solid catalysts for several reactions related to the components of lignocellulosic biomass 
and/or some platform molecules. The diversity of contributions in this Special Issue reflects the relevance of this type of feedstock, which is still not sufficiently exploited since it could allow us to replace, at least partially, the traditional fossil fuels as a source of energy and chemicals.

Guerrero-Torres et al. [3] tested Cu-based catalysts supported on sepiolite for the vaporphase hydrogenation of furfural to obtain furfuryl alcohol as the main product. Furfural can be obtained by dehydration of C5 monomers, including xylose and arabinose from the acid hydrolysis of hemicellulose. Its growing annual world production is currently about 430,000 tons and it is considered as one of the most promising building-blocks produced from lignocellulose as it can be employed for the synthesis of a wide variety of chemicals and biofuels. Furfuryl alcohol possesses great potential as it can be utilized to produce resins, fibers and rubbers as well as for the synthesis of agrochemicals and bioproducts. Following reports on the interaction of $\mathrm{Cu}$-based catalysts with the carbonyl group of furfural, with furfuryl alcohol being the main product, Guerrero-Torres et al. studied the use of an inexpensive fibrous phyllosilicate, such as sepiolite, as a support, incorporating basic or amphoteric metal oxides such as $\mathrm{MgO}, \mathrm{ZnO}$ or $\mathrm{CeO}_{2}$ to improve the catalytic performance. They found that the addition of these metal oxides enhanced the dispersion of metallic $\mathrm{Cu}$ nanoparticles, which directly affected the catalytic performance, with furfuryl alcohol being the main product in all cases. This fact was attributed to these metal oxides decreasing the crystal size of $\mathrm{Cu}$ particles, subsequently increasing the amount of available $\mathrm{Cu}$ sites. They also detected the presence of 2-methylfuran mainly for $\mathrm{ZnO}$ containing catalysts due to these catalysts showing higher acidity, which promoted the hydrogenolysis of furfuryl alcohol. However, these acid sites are also related to catalytic deactivation, decreasing both furfural conversion and furfuryl alcohol and 2-methylfuran yields over time on stream. Despite this deactivation, these catalysts are very stable compared with other catalysts reported in the literature since furfural conversion was above $80 \%$ after a $5 \mathrm{~h}$ reaction using $\mathrm{MgO}$ and $\mathrm{ZnO}$.

On the other hand, Hoĉevar et al. [4] tested noble and transitional metals $(\mathrm{Ru}, \mathrm{Pt}, \mathrm{Rh}$, $\mathrm{Ni}$, NiMo) on various supports $\left(\mathrm{C}, \mathrm{SiO}_{2}, \mathrm{Al}_{2} \mathrm{O}_{3}\right)$ for hydrodeoxygenation (HDO) reaction of mucic acid. One of the main lignocellulose components is cellulose, which is a crystalline polysaccharide formed by glucose units linked through beta-1,4-d-glycosidic bonds. These glucose monomers can be oxidized at both terminal C-atoms, giving rise to a group of dicarboxylic sugar acids denominated aldaric acids, mainly glucaric or mucic acids. The high oxygen/carbon ratio existing in cellulose makes its use difficult for transportation fuel. Therefore, the HDO of aldaric acids derived from cellulose is a source of great interest in the industry. These authors found that mucic-1,4-lactone was formed in the absence of a catalyst under an inert $\mathrm{N}_{2}$ atmosphere. However, dehydroxylation, hydrogenation, decarbonylation, decarboxylation and cyclization took place in the catalytic hydrotreatment, obtaining partially and completely deoxygenated products with a chain length of C3-C6 atoms. They compared the catalytic behaviors of different traditional HDO catalysts based on noble and transition metals $(\mathrm{Ru}, \mathrm{Pt}, \mathrm{Rh}, \mathrm{Ni}, \mathrm{NiMo})$ on supports with different acidity values, such as $\mathrm{C}, \mathrm{SiO}_{2}$ and $\mathrm{Al}_{2} \mathrm{O}_{3}$. On the one hand, the $\mathrm{NiMo} / \mathrm{Al}_{2} \mathrm{O}_{3}$ catalyst provided better catalytic results than a noble metal catalyst at lower temperatures. The main products detected after HDO reaction were tetrahydro-2-furfuryl alcohol, adipic acid, 2-hydroxy pentanoic acid, levulinic acid, 2-furoic acid, 2-pentenoic acid and 2-hydroxy hexanoic acid. These chemicals are currently relevant platform products but very high yields were not achieved in any case. On the other hand, in the case of noble metals such as $\mathrm{Ru}$ and $\mathrm{Rh}$, high catalytic activities were found for the transformation of mucic acid to hydrocarbons but the yield of adipic acid did not exceed 5\%. By using water for an eco-friendly process, the highest values of activity were detected for $\mathrm{Ru} / \mathrm{C}, \mathrm{Ru} / \mathrm{SiO}_{2}$ and $\mathrm{Rh} / \mathrm{SiO}_{2}$ at low temperatures.

Dabros et al. [5] synthesized a Ni-MoS 2 catalyst with $\mathrm{MgAl}_{2} \mathrm{O}_{4}$ as support to carry out the HDO of cellulose and lignin type model compounds, such as ethylene glycol, cyclohexanol, acetic acid and phenol. They chose this water and sulfur tolerant support as oxygen 
is removed as water in HDO reactions and biomass frequently contains sulfur which could deactivate the transition metal-based catalysts by poisoning. They also studied the HDO of both cellulose- and lignin-derived model compounds in order to determine the competitive reactions that take place during the HDO reaction by using real biomass-based feedstocks. They detected considerable differences in the reactivity of different compounds for HDO reactions. Thus, for example, acetic acid demonstrated a very high reactivity in such a way that it was able to block the reactor inlet by carbon deposition after only $2 \mathrm{~h}$ on stream. However, phenol showed limited reactivity, giving rise to low yields for alkyl substitution reactions. It should be noted that although ethylene glycol conversion occurred easily both in the absence and presence of phenol and cyclohexanol, demonstrating that different active sites were required, the deoxygenation of cyclohexanol was considerably decreased due to the presence of ethylene glycol. This fact can be attributed to a competitive adsorption and carbon deposition on acid sites. Then, they concluded that the immediate stabilization of reactive cellulose fragments before condensation would be beneficial in order to decrease coking and avoid the inhibition of HDO reaction for less reactive oxygenates. They also confirmed that deposited carbon could be removed to regenerate the Ni-MoS 2 catalyst by oxidation and re-sulfidation, demonstrating its potential for HDO reactions.

Although hemicellulose and cellulose fractions have been more studied in the literature due to lignin valorization is more complicated, lignin is a feedstock rich in aromatics and its valorization is a key factor for improving the economic balance of biorefineries. Bjelić et al. [6] decided to study a model compound, eugenol, which contains hydroxy, methoxy, and allyl functional groups on an aromatic ring, similarly to lignin monomers. They prepared magnetically separable $\mathrm{Ru}$ nanoparticles that were tested for HDO of eugenol in a batch reactor at $275^{\circ} \mathrm{C}$ under $5 \mathrm{MPa}$ of $\mathrm{H}_{2}$. Moreover, they evaluated the influence of pretreatment temperature $\left(300-750{ }^{\circ} \mathrm{C}\right)$ for support, $\mathrm{C}-\mathrm{Fe}_{2} \mathrm{O}_{3}$, on the product distribution and checked that the catalyst was inactive if this pretreatment was not carried out. By the increase in this pretreatment temperature, both hydrogenation and deoxygenation of saturated cyclic species were promoted, attaining better catalytic results than those found for commercial carbon-supported ruthenium, achieving the maximum value at an annealing temperature of $600{ }^{\circ} \mathrm{C}$. Values for 4-propyl-cylohexanol and propyl-cyclohexane yields of about $80 \%$ were found for catalysts treated at 500 and $600{ }^{\circ} \mathrm{C}$ for 100 and $125 \mathrm{~min}$, respectively, under $\mathrm{H}_{2}$ pressure at $275^{\circ} \mathrm{C}$. It should be noted that a prominent amount of 4-propyl-phenol was detected when this pretreatment was carried out at $750{ }^{\circ} \mathrm{C}$, with lower selective ring hydrogenation in spite of an improvement of catalytic activity not being found. They confirmed that the catalyst treated at $600{ }^{\circ} \mathrm{C}$ exhibited a better catalytic performance in terms of deoxygenation of saturated intermediates compared to a similar commercial catalyst based on $\mathrm{Ru} / \mathrm{C}$, where the dispersion of $\mathrm{Ru}$ nanoparticles was the main reason for this activity. Thus, they confirmed that the contribution of Fe particles to catalytic activity was scanty or even non-existent.

Finally, Parto et al. [7] evaluated the liquefaction of lignosulfonate in ethanol and ethyleneglycol media by using Ni-based catalysts considering that lignosulfonate is a technical lignin that is obtained as a byproduct from the sulfite pulping process where sulfonate groups are introduced to the aliphatic chains via C-S bonds. They checked that the liquefied fractions, regarded as oil, formed mainly by dimers and oligomers, were very similar in both solvents, ethanol and ethyleneglycol (31 and $32 \mathrm{wt} \%$, respectively). They also detected that oil fractions obtained from depolymerization in ethanol exhibited the formation of lower molecular weight compounds than from that carried out in ethyleneglycol. The latter also showed higher activity when inhibiting condensation reactions. On the other hand, ethanol was relatively stable under the reaction conditions studied, while ethyleneglycol was transformed to diethylene glycol, triethylene glycol and tetraethylene glycol, which was probably catalyzed by $\mathrm{SO}_{3} \mathrm{H}$ groups existing in the lignosulfonate. Although the nickel phase was supported on different materials such as activated carbon, silica, zirconia and alumina, significant differences were not found in the conversion of lignosulfonate. Despite 
the detection of NiS after analysis of the spent catalyst by XRD and ICP analyses, sulfur stability and the reusability of the Ni-based catalyst were demonstrated.

In conclusion, the works in this Special Issue compile relevant progress in the development of heterogeneous catalysts for biomass valorization. We would like to express our sincere thanks to all authors for their valuable contributions as well as the editorial team of Catalysts for their kind support, without which this Special Issue would not have been possible.

Author Contributions: C.G.-S., writing—original draft preparation; C.G.-S., writing—review and editing; R.L., writing - review and editing. All authors have read and agreed to the published version of the manuscript.

Funding: This research received no external funding.

Conflicts of Interest: The authors declare no conflict of interest.

\section{References}

1. Wang, F.; Ouyang, D.; Zhou, z.; Page, S.J.; Liu, D.; Zhao, X. Lignocellulosic biomass as sustainable feedstock and materials for power generation and energy storage. J. Energy Chem. 2021, 57, 247-280. [CrossRef]

2. Serrano, L.; Cecilia, J.A.; Garcia-Sancho, C.; García, A. Lignin Depolymerization to BTXs. Top. Curr. Chem. 2019, 377, 26. [CrossRef] [PubMed]

3. Guerrero-Torres, A.; Jiménez-Gómez, C.P.; Cecilia, J.A.; García-Sancho, C.; Quirante-Sánchez, J.J.; Mérida-Robles, J.M.; MairelesTorres, P. Influence of the incorporation of basic or amphoteric oxides on the performance of Cu-based catalysts supported on sepiolite in furfural hydrogenation. Catalysts 2019, 9, 315. [CrossRef]

4. Hoĉevar, B.; Miha, G.; Likozar, B. Aqueous dehydration, hydrogenation, and hydrodeoxygenation reactions of bio-based mucic acid over Ni, NiMo, Pt, Rh, and Ru on neutral or acidic catalyst supports. Catalysts 2019, 9, 286. [CrossRef]

5. Dabros, T.M.H.; Andersen, M.L.; Lindahl, S.M.; Hansen, T.W.; Høj, M.; Gabrielsen, J; Grunwaldt, J.D.; Jensen, A.D. Hydrodeoxygenation (HDO) of aliphatic oxygenates and phenol over $\mathrm{NiMo} / \mathrm{MgAl}_{2} \mathrm{O}_{4}$ : Reactivity, inhibition, and catalyst reactivation. Catalysts 2019, 9, 521. [CrossRef]

6. Bjelić, A.; Grilc, M.; Gyergyek, S.; Kocjan, A.; Makovec, D.; Likozar, B. Catalytic hydrogenation, hydrodeoxygenation, and hydrocracking processes of a lignin monomer model compound eugenol over magnetic $\mathrm{Ru} / \mathrm{C}-\mathrm{Fe}_{2} \mathrm{O}_{3}$ and mechanistic reaction microkinetics. Catalysts 2018, 8, 425. [CrossRef]

7. Parto, S.G.; Christensen, J.M.; Pedersen, L.S.; Tjosås, F.; Jensen, A.D. Solvothermal conversion of lignosulfonate assisted by Ni catalyst: Investigation of the role of ethanol and ethylene glycol as solvents. Catalysts 2018, 8, 502. [CrossRef] 